\title{
Recursos Semióticos em Atividades de Modelagem Matemática
}

\author{
Semiotic Resources in Mathematical Modelling Activities
}

Lourdes Maria Werle de Almeida*a; Tania Camila Kochmanscky Goulart ${ }^{\mathrm{b}}$

${ }^{a}$ Universidade Estadual de Londrina. PR, Brasil.

${ }^{\mathrm{b} U N I F I L . ~ P R, ~ B r a s i l . ~}$

*E-mail: lourdes@uel.br

\begin{abstract}
Resumo
Neste artigo dirigimos nossa atenção à questão: quais recursos semióticos são ativados em atividades de modelagem matemática e como eles colaboram para o desenvolvimento da atividade? Nossas argumentações são fundamentadas, por um lado, em um quadro teórico que considera características da modelagem matemática bem como elementos relativos ao uso de recursos semióticos em atividades de ensino e aprendizagem e a constituição de pacotes semióticos. Por outro lado, consideramos uma pesquisa empírica em que atividades de modelagem matemática são desenvolvidas por alunos de uma disciplina de Cálculo Diferencial e Integral em um curso de Ciência da Computação. A pesquisa tem natureza qualitativa com cunho interpretativo. As análises nos permitem inferir que os alunos fazem uso de recursos semióticos de naturezas diversas de modo que se constituem pacotes semióticos relativamente às ações dos alunos nas diferentes fases do desenvolvimento de uma atividade de modelagem matemática. A ativação dos recursos semióticos bem como a sua colaboração para o desenvolvimento da atividade de modelagem matemática é ao mesmo tempo sincrônica e diacrônica de modo que não é possível afirmar especificamente quando um recurso atua de forma isolada ou conjuntamente com outros para potencializar a comunicação e organizar o pensamento. O que se pode concluir é que diferentes recursos semióticos atuam de maneira colaborativa para fomentar estas ações.
\end{abstract}

Palavras-chave: Educação Matemática. Modelagem Matemática. Recurso Semiótico. Pacote Semiótico.

\begin{abstract}
In this article we focus our attention on the question: what semiotic resources are activated in mathematical modeling activities and how do they collaborate in the development of the activity? Our arguments are based, on the one hand, on a theoretical framework that considers characteristics of mathematical modeling as well as elements related to the use of semiotic resources in teaching and learning activities. On the other hand, we consider an empirical research in which mathematical modeling activities are developed by students from a Differential and Integral Calculus discipline in a Computer Science course. From a qualitative research and interpretive nature, the analyzes allow us to infer that students make use of semiotic resources of different natures so that they constitute semiotic packages in relation to students'actions in the different phases of the development of a modeling activity mathematics. The activation of semiotic resources as well as their collaboration for the development of the mathematical modeling activity is both synchronous and diachronic so that it is not possible to state specifically when a resource acts in isolation or in conjunction with others to enhance communication and organize the thought. What can be concluded is that different semiotic resources work collaboratively to foster these actions.
\end{abstract}

Keywords: Mathematical Education. Mathematical Modeling. Semiotic Resource. Semiotic Package.

\section{Introdução}

Estudos relativos à Semiótica na Educação Matemática têm sido recorrentes nas últimas décadas levando em consideração diferentes elementos relativos ao ensino e à aprendizagem da matemática e em diferentes contextos educacionais (Arzarello, 2006, Mildenhall, 2013, Panero, Arzarello, \& Sabena, 2016, Almeida \& Silva, 2018, Radford, Schubring \& Seeger, 2008; Almeida \& Silva, 2017, Almeida \& Silva, 2018a; Steinbring, 2006).

O que se pode observar a partir desses estudos é que a lente semiótica oferece elementos para abordar o ensino e a aprendizagem considerando tanto aspectos cognitivos quanto aspectos didáticos associados às atividades da sala de aula. No presente artigo direcionamos essa lente para o desenvolvimento de atividades de modelagem matemática.

Segundo Almeida e Brito (2005), a modelagem matemática pode ser definida como uma abordagem, por meio da Matemática, de uma situação-problema que, de modo geral, não é matemática.

Um aspecto relevante para o contexto do presente artigo refere-se às ações, aos meios e aos $\operatorname{artefatos}^{1}$ usados pelos alunos e professores no desenvolvimento de atividades de modelagem matemática na sala de aula. Ou seja, que recursos de expressão e de comunicação são usados pelos modeladores ao desenvolver a atividade? Nosso olhar para esta questão é mediado pela semiótica. Particularmente por uma lente

1 Segundo Abbagnano (2007) trata-se de um objeto produzido por qualquer atividade humana. Para ser considerado artefato, o objeto deve manifestar a intenção, preexistente à sua construção, de utilizá-lo com determinada finalidade. 
semiótica que considera os chamados recursos semióticos.

Arzarello (2006) argumenta que no contexto da sala de aula conjugam-se recursos linguísticos e extralinguísticos valendo-se de da oralidade, da escrita e até mesmo de ferramentas da tecnologia digital, como é o caso de imagens e gráficos, por exemplo. Segundo Mavers (2004), estes recursos são considerados recursos semióticos.

Todavia, o que tem sido investigado nas últimas décadas em relação aos recursos semióticos é que, para além de considerálos isoladamente nas atividades da sala de aula, a articulação de diferentes recursos bem como sua complementaridade para a comunicação na sala de aula e para a aprendizagem dos alunos deve ser favorecida nas atividades na sala de aula (Arzarello, 2006; Mavers, 2004; Panero, Arzarello, \& Sabena, 2016; Mildenhall, 2013).

Segundo Arzarello (2006), é necessário considerar a variedade de processos e recursos semióticos que ocorrem na sala de aula e como eles se articulam nas ações dos alunos para promover a aprendizagem. Com esta finalidade o autor caracteriza os pacotes semióticos. Segundo o autor, um pacote semiótico é composto por um conjunto de recursos ativados por meio de diferentes ações e com caráter intencional, estabelecendo relações entre signos e seus significados subjacentes.

No presente artigo trazemos para o âmbito de atividades de modelagem matemática a investigação do uso de pacotes semióticos considerando a possibilidade de que a articulação de diferentes recursos semióticos pode incrementar as ações de alunos e professores no desenvolvimento dessas atividades. Assim, a questão que nos propomos a investigar é: quais recursos semióticos são ativados em atividades de modelagem matemática e como eles colaboram para o desenvolvimento da atividade?

Assim, por um lado estruturamos um quadro teórico que considera características da modelagem matemática bem como elementos relativos ao uso de recursos semióticos em atividades de ensino e de aprendizagem. Por outro lado, consideramos uma pesquisa empírica em que atividades de modelagem matemática são desenvolvidas por alunos de uma disciplina de Cálculo Diferencial e Integral em um curso de Ciência da Computação.

\section{Modelagem Matemática}

A Modelagem Matemática refere-se, em termos gerais, à busca de uma solução para uma situação-problema por meio de modelos matemáticos (Bassanezi, 2002, Blum, 2015, Borromeo Ferri, 2018, Almeida, Silva, \& Vertuan, 2016, Greefrath, Hertleif, \& Siller, 2018).

Quando essa dinâmica caracterizada como modelagem matemática é incorporada às aulas em diferentes níveis de escolaridade, os alunos passam a ser corresponsáveis pela investigação de uma situação-problema em que definem e resolvem um problema usando matemática, de modo que a modelagem se torna uma abordagem, por meio da Matemática, de uma situação-problema não necessariamente matemática (Almeida \& Brito, 2005).

Almeida (2010) propõe que uma atividade de modelagem matemática tem origem em uma situação inicial em que se identifica um problema, e tem como ponto de chegada uma situação final em que uma solução para o problema é apresentada.

No caminho entre estas situações, identificamse procedimentos que vêm sendo caraterizados com denominações tais como etapas, fases ou simplesmente estágios do desenvolvimento da atividade de modelagem matemática (Blum, 2015, Borromeo Ferri, 2018, Almeida, Silva, \& Vertuan, 2016, Bassanezi, 2002, Meyer, 2020, Almeida, 2018). É consenso que não há encaminhamentos matemáticos previamente definidos em relação a estes procedimentos.

Particularmente, neste artigo, vamos nos apoiar na configuração de uma atividade de modelagem matemática como apresentada em Almeida, Silva \& Vertuan (2016). Neste contexto, ao desenvolvimento de uma atividade de modelagem associam-se quatro fases: inteiração, matematização, resolução, interpretação e validação dos resultados.

A inteiração, fase que conduz à formulação do problema, é caracterizada pela ação dos alunos de inteirar-se da situação, de buscar informações, de identificar um problema a ser resolvido bem como pela realização de simplificações e definição de hipóteses. Matematização é a fase de transição da linguagem em que a situação e o problema são apresentados em linguagem matemática. Simplificações e hipóteses podem ser retomadas de modo a dar-lhes a roupagem matemática pertinente em cada situação. A fase de resolução consiste na construção de um modelo matemático. Finalmente a fase de interpretação e validação dos resultados é aquela em que se dá a análise da resposta e a interpretação em relação ao problema não matemático bem como a validação dessa resposta.

Segundo Almeida, Silva \& Vertuan (2016), não há uma prescrição linear para estas fases de modo que alunos e professores podem movimentar-se de uma fase para outra e retomar fases anteriores sempre que isto se mostrar adequado ou pertinente para a construção de uma solução para um problema não matemático por meio da matemática.

Um aspecto relevante para o contexto do presente artigo refere-se às ações, aos meios e aos artefatos usados pelos alunos e professores no desenvolvimento da atividade de modelagem considerando estas fases. Ou seja, que recursos de expressão e de comunicação são usados pelos modeladores ao desenvolver a atividade? Nosso olhar para esta questão é mediado pela semiótica. Mais especificamente, por uma lente semiótica que considera os chamados recursos semióticos.

\section{Semiótica}

A semiótica é a ciência geral de todos os tipos de linguagem, 
em outras palavras é a ciência que estuda os signos. Santaella (2016, p.8) define o signo como

qualquer coisa de qualquer espécie (uma palavra, um livro, uma biblioteca, um grito, uma pintura, um museu, uma pessoa, uma mancha de tinta, um vídeo etc.) que representa uma outra coisa chamada de objeto do signo, e que produz um efeito interpretativo em uma mente real ou potencial.

No que se refere ao âmbito da Matemática, Santaella (2016, p.3) pondera que "não há pensamento que possa se desenvolver apenas através de símbolos" e ainda considera que nem mesmo o raciocínio puramente matemático pode dispensar uma variedade de signos.

Conforme afirma Steinbring (2006), os signos usados no contexto da Matemática podem ser vistos como instrumentos para codificar, comunicar, e viabilizar a expressão e a representação dos objetos matemáticos. Os signos, contudo, não têm significado por si só, mas esse deve ser produzido pelo aluno por meio de mediações e para contextos de referência específicos.

Segundo Ernest (2006), abordar o ensino e a aprendizagem numa perspectiva semiótica é uma iniciativa promissora mediante a qual se busca compreender signos e suas regras de produção. A produção e manipulação de signos de naturezas diversas viabilizam aos alunos novas interpretações do que conhecem sem abrir mão do que já estava previamente em sua estrutura cognitiva.

Várias pesquisas têm se endereçado às atividades semióticas dos alunos no âmbito de aulas de Matemática (Panero, Arzarello \& Sabena, 2016; Almeida \& Silva, 2017). Resultados indicam que a aprendizagem, quando associada à produção e ação de diferentes signos, pode se constituir relativamente a uma variedade de representações e significados do objeto matemático.

Nessa perspectiva que considera o potencial de uma diversidade de signos, parece relevante levar em conta diferentes modos de organização, criação e desenvolvimento de signos pelos alunos no decorrer de um período do tempo. Com esta finalidade dirigimos nossa atenção aos chamados recursos semióticos.

\section{Recursos Semióticos}

Para realizar uma análise semiótica abrangente considerando a diversidade sígnica a que se refere Santaella (2016), é preciso ampliar a estrutura do que constitui os sistemas semióticos, visando possibilitar a interpretação do fenômeno didático na sala de aula (Almeida \& Silva, 2018;,Arzarello, 2006).

Neste sentido, é preciso considerar também signos menos convencionais, mas que fazem parte de todo o processo de comunicação que acontece na sala de aula. Estes sistemas semióticos mais amplos, entretanto, levam em consideração também aspectos holísticos e idiossincráticos no decorrer da construção e ação com signos na sala de aula. Neste contexto, emerge a ideia de recursos semióticos (Arzarello, 2006,
Mavers, 2004; O’halloran et al., 2018).

A noção de recursos semióticos remete à identificação de diferentes recursos escolhidos pelos sujeitos, voluntaria ou involuntariamente, na construção e uso de signos de naturezas diversas. Mavers (2004) entende que os recursos semióticos envolvem ações e artefatos que os sujeitos usam para fins comunicativos. Segundo o autor, os sujeitos combinam o uso de recursos linguísticos e extralinguísticos de modo que gestos, olhares, registros escritos, software, expressões matemáticas e imagens gráficas, entre outros, constituem recursos semióticos.

Segundo Ernest (2006, p.69), os recursos semióticos diversos são ativados no interior de um sistema semiótico o qual é caracterizado a partir de três aspectos:

Primeiro, há um conjunto de signos, cada um dos quais possivelmente, possa ser pronunciado, falado, escrito, desenhado ou codificado eletronicamente [...]. Segundo, existe um conjunto de regras de produção de signos, para produzir ou proferir signos atômicos (únicos) e moleculares (compostos) [...]. Terceiro, há um conjunto de relações entre os signos e seus significados incorporados em uma estrutura de significado subjacente.

Segundo Lim (2019), considerar os diferentes recursos semióticos representa um marco na investigação da atividade semiótica, pois passa-se a considerar não os signos isoladamente, mas a sua articulação para a capacidade de manifestar o que se pensa e o que sabe sobre determinado objeto ou assunto.

A atuação de diferentes recursos semióticos deve se dar de forma integrada de modo que os sujeitos, ao produzirem signos que comunicam, organizam e estruturam o pensamento, beneficiem-se da integração para fomentar a qualidade da comunicação (Arzarello, 2006, Lim, 2019, Mavers, 2004, Mildenhall, 2013).

Segundo O’Halloran et al. (2018), a utilização de vários recursos semióticos viabiliza uma abordagem holística para o que se deseja comunicar por meio dessa utilização. Nesse contexto, Moro et al. (2015) consideram que o ensino e a aprendizagem sempre se utilizam de diferentes recursos semióticos, incluindo oralidade (como por exemplo, fala, olhar, gestos), escrita e uso de imagens bem como recursos áudio visuais mediados, em muitas situações, por ferramentas digitais. Neste sentido, os recursos semióticos são também contextuais, sinalizando a pertinência de um espaço pessoal dos indivíduos num meio social.

Panero et al. (2016) neste contexto, argumentam que quando dois ou mais recursos semióticos convergem para uma mesma função no interior de uma atividade, o uso conjunto destes recursos favorece a ação comunicativa.

Para Arzarello (2006), é necessário pensar numa lente semiótica capaz de considerar a variedade de recursos semióticos que se identificam na sala de aula. Com esta finalidade o autor caracteriza uma estrutura que, em sua opinião, alarga a noção de uso de recursos semióticos e passa 
a considerar a articulação desses recursos e sua finalidade: os pacotes semióticos. Segundo o autor, um pacote semiótico é composto por um conjunto de signos produzidos por meio de diferentes ações e com caráter intencional, estabelecendo relações entre os signos e seus significados subjacentes. Neste contexto,

fala, gestos e representações escritas (de esboços e diagramas a símbolos matemáticos) são exemplos de três tipos diferentes de recursos semióticos que, em conjunto e também incorporando as relações entre eles, constituem o que chamamos de pacote semiótico. Este pacote se modifica de forma dinâmica no decorrer do tempo (Arzarello, 2006, p. 284).

Do ponto de vista da aprendizagem, segundo Arzarello (2006), a caracterização de um pacote semiótico em atividades na sala de aula pode oferecer condições ao professor de elucidar o funcionamento cognitivo subjacente à diversidade de processos matemáticos relativos à atividade. Por outro lado, o professor precisa ter consciência das ações dos alunos, acompanhando a ativação dos recursos semióticos de seus alunos para determinar a configuração de condições que irão fomentar as experiências de aprendizagem dos alunos e adaptar suas intervenções em cada atividade didática específica.

Particularmente, Arzarello (2006) argumenta que o potencial da ativação de pacotes semióticos para a aprendizagem da Matemática, pode ser inferido por meio de dois tipos de análise: sincrônica e diacrônica. A análise sincrônica se dirige às relações entre os diferentes recursos semióticos ativados e coordenados simultaneamente pelo aluno em um determinado momento. A análise diacrônica investiga a evolução dos recursos ativados em momentos sucessivos, buscando evidências da dinâmica da articulação no decorrer do tempo.

Estas análises trazem evidências de que as ações dos sujeitos, além de estarem vinculadas às intencionalidades, fomentam a ativação de diferentes maneiras de codificar e manipular informações. Neste sentido, um pacote semiótico não pode ser considerado a justaposição de recursos semióticos e de suas relações, mas "constitui um todo cujas componentes distinguimos apenas para fins de análise" (Arzarello, 2006, p. 281). Assim, uma mudança entre os componentes do pacote gera um novo pacote semiótico que surge de outro já existente. Neste sentido ponderamos que "uma atividade matemática pode ser caracterizada pela riqueza do pacote semiótico que ela ativa" (Arzarello, 2006, p. 279).

Levando em consideração a relevância do uso de diferentes recursos semióticos nas atividades matemáticas, no presente artigo dirigimos nossa atenção à ativação de recursos semióticos em atividades de modelagem matemática.

\section{Apresentação dos Dados}

Para investigar quais recursos semióticos são ativados em atividades de modelagem matemática e como eles colaboram para o desenvolvimento da atividade realizamos uma pesquisa empírica em que atividades de modelagem são desenvolvidas por alunos de um curso de Ciência da Computação na disciplina de Cálculo Diferencial Integral (CDI) no segundo ano do curso. Levando em consideração a extensão desse texto, dirigimos nossa atenção a uma das atividades cujo desenvolvimento foi realizado no decorrer de seis aulas de sessenta minutos cada uma. A professora da disciplina é uma das autoras deste artigo e propôs a atividade para uma turma de 34 alunos, separados em 6 grupos ( 5 grupos de 6 alunos e 1 grupo de 4 alunos). Nossa discussão no presente artigo leva em consideração dois desses grupos, definidos a partir de nosso interesse em identificar e analisar a variedade de recursos semióticos ativados pelo grupo no desenvolvimento da atividade.

Os dados que subsidiam as nossas argumentações são provenientes das falas associadas a gestos e meios de expressão, das interações entre os participantes de cada grupo bem como das gravações de vídeos das aulas e das apresentações que cada grupo fez na aula. Estas gravações foram transcritas pela professora e associadas às suas anotações em diário de campo realizadas no decorrer das aulas em que a atividade foi desenvolvida. Outra ferramenta de coleta de dados foi o uso do software $\mathrm{OBS}^{2}$ que permitiu que a imagem da tela do computador fosse capturada de maneira simultânea com o som das falas dos alunos ao desenvolverem a atividade. Além disso, também foram capturadas as telas dos relatórios escritos dos alunos postados no aplicativo Google Classroom $\AA^{3}$.

Os grupos a que nos referimos são identificados por G2 e G4. G2 é formado por seis alunos de modo que os alunos são identificados por G2A1 até G2A6. Já para os alunos de G4 usamos G4A1 até G4A4 para nos referirmos a cada um dos quatro alunos desse grupo. Na transcrição dos diálogos com participação da professora usamos a letra $\mathrm{P}$ para identificar suas falas. Vale ressaltar que os alunos já haviam tido experiências anteriores com atividades de modelagem matemática de modo que este não era seu primeiro contato com atividades dessa natureza.

Nossa opção metodológica caracteriza uma pesquisa qualitativa de cunho interpretativo. Nossas análises, sincrônica e diacrônica dos dados coletados, consideram por um lado, os recursos semióticos ativados ou produzidos pelos alunos nas diferentes fases do desenvolvimento da atividade de modelagem matemática. Por outro lado, associamos a isso a manipulação e a escolha de cada recurso de acordo com a intencionalidade de cada grupo de modo que possamos inferir sobre os pacotes semióticos caracterizados nas diferentes fases

2 Sigla para Open Broadcaster Software: permite a gravação de tela do computador com o áudio.

3 Recurso da Google ${ }^{\circledR}$ voltado para as práticas de educacionais - a faculdade possui licença para o uso. 
do desenvolvimento da atividade de modelagem matemática.

\subsection{A atividade de modelagem matemática desenvolvida: a moeda Bitcoin}

Para o desenvolvimento da atividade a que nos referimos nesse artigo a professora sugeriu aos alunos a temática da moeda Bitcoin (BTC). Os alunos da disciplina, prontamente se interessaram pelo tema, o que se pode supor relacionado à sua familiaridade ou afinidade com a área do curso, Ciência da Computação. Para introduzir o tema, a professora organizou um conjunto de informações que foram apresentadas aos alunos conforme indica a Figura 1 e que constituem uma primeira fonte de informação dos alunos para o desenvolvimento da atividade.

Figura 1 - Informações sobre a moeda Bitcoin

\section{A Moeda Bitcoin}

Em 31 de outubro de 2008 nascia o Bitcoin (BTC), a primeira moeda virtual criptografada e descentralizada do mundo, criada por Satoshi Nakamoto. O BTC basicamente um arquivo digital on-line. Funciona como moeda alternativa que se diferencia das moedas convencionais e dispensa intermediários nas transações de compra e venda. O registro das transações é denominado mineração. Na medida em que a rede de mineradores vai se ampliando, as transações vão se tornando mais complexas, mas também mais rentáveis.

As transações são agrupadas em forma de blocos - uma espécie de arquivo com as informações da moeda- que uma vez criados são anexados a uma estrutura de dados denominada BlockChain.

Em 03 de janeiro de 2009 foi criado o primeiro bloco que geraria 50 Bitcoins. Desde 2012, o número de Bitcoins por bloco é reduzido pela metade a cada quatro anos. Portanto, o número total de Bitcoins em circulação deverá crescer em um ritmo cada vez mais lento. No gráfico a seguir está o número de Bitcoins que foram minerados até março de 2019.

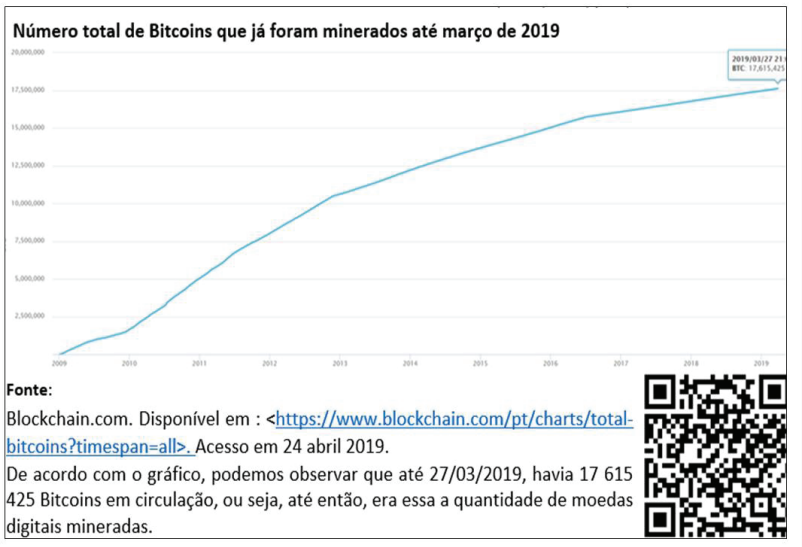

Fonte: As autoras.

As informações da Figura 1 foram discutidas e em seguida os alunos formaram grupos para estruturar o que seria investigado por cada grupo relativamente a essa temática. Assim, cada grupo deveria definir um problema e propor uma solução. Apresentamos os encaminhamentos de dois desses grupos.

Um dos grupos, referido aqui como grupo G2, ao iniciar desenvolvimento da atividade, imediatamente percebeu que as informações apresentadas pela professora não eram suficientes. Assim, os alunos usaram o aplicativo de celular para escanear o $Q R \quad C O D E^{4}$ incluído nas informações fornecidas pela professora. Ao usar este recurso, os alunos tinham acesso, em tempo real, à quantidade de moedas mineradas e podiam explorar o seu comportamento (Figura 2e e 2f). Além disso, os alunos utilizaram também texto escrito, falas, gestos, computador e sites (Figura 2).

Figura 2 - Recursos semióticos usados pelo G2 na investigação do problema

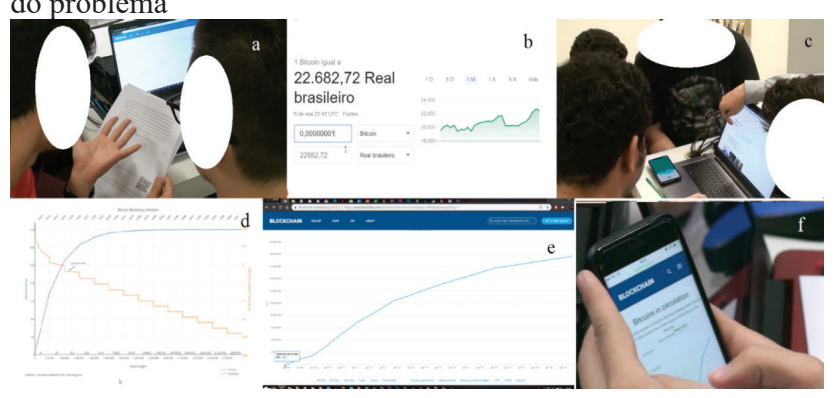

Fonte: As autoras

$\mathrm{O}$ aluno G2A2, explorando informações relativas ao tema na internet (Figura 2c), encontrou uma calculadora de BTCs cujo uso é on-line e que, além de fazer a conversão da moeda para a moeda oficial do Brasil (real), apresenta representações gráficas da situação (Figura 2be Figura 2d). Motivados pelas informações de A2, os alunos do grupo iniciaram suas discussões relativas ao desenvolvimento da atividade de modelagem matemática.

G2A1: Mas se você olhar pra esse gráfico, vê que isso a gente não pode prever, é muito instável(referindo-se aos gráficos das Figuras $2 b$ e $2 d$ )

G2A3: É que vai dividindo, dividindo, até que não dá mais pra dividir, deve ter alguma coisa no código deles que não deixa dividir mais a moeda.

G2A5: Mas este gráfico que a gente tá estudando (Figura 2e) é da data e da quantidade de BTC que já foi minerado. Não fala de valor em dinheiro aqui. Ele tá indo em exponencial aqui. É que nem o da bateria do celular (fazendo referência a uma atividade já desenvolvida na disciplina), não é que vai estabilizar, vai carregando, vai carregando até ficar estável (diz o aluno ao apontar para a tela do computador).

G2A3: Mas só que neste caso nunca vai ficar estável, é quase uma assíntota (fazendo uma associação com um conteúdo que já havia estudado na disciplina).

G2A4: Acho então que a gente pode achar esta curva aqui (referindo-se à curva apresentada no site) e depois fazer um limite dela... vai dar pra ver como ela tá. Vamos ver com a professora.

G2A3: Professora, a gente pensou de ver se quando a moeda vai acabar...

P: Mas por que pensaram em fazer isso?

G2A1: Assim... se ela vai crescendo e chega uma hora que estabiliza, a gente imagina que é aí ela vai acabar e é isso que a gente vai testar, já que ela é limitada como fala no site (referindo-se às informações encontradas em sites pelos alunos)

P: Mas quais os dados vocês têm? Já olharam para eles?

G2A3: A gente pensou nisso porque parece que a moeda está acabando, mas nunca vai acabar, apesar da curva ficar quase reta.

P: Mas como sabem se isso vai ou não mudar?

G2A4: É que a gente sabe que qualquer moeda virtual é limitada e conforme vai minerando, elas vão ficando escassas. 
A partir dessa discussão e das informações encontradas relativas ao Bitcoin, o grupo decidiu que o problema que iriam resolver nessa atividade é: Investigar o comportamento da moeda Bitcoin no decorrer do tempo, considerando que há uma quantidade limitada dessa moeda disponível para comercialização. Com essa finalidade iriam construir um modelo matemático que lhes permita determinar a quantidade de Bitcoin em cada ano e também fazer estimativas para anos futuros.

Fazendo uso das informações relativas à quantidade da moeda on-line e em tempo real, os alunos montaram uma tabela com o ano e o número de BTC em cada ano (ver Figura 3). A partir dos dados da tabela, escolheram fazer uma simplificação: registrar sempre a mesma data em cada ano. Essa escolha foi fundamentada para "estabelecer um padrão nos dados coletados" - fala do aluno G2A2.

Visando resolver o problema proposto a partir das informações que possuíam, os alunos definiram a hipótese: a quantidade de moeda a ser minerada é limitada. Usando essa hipótese, o grupo pretendia construir um modelo matemático que representasse a quantidade de moedas minerada a cada ano a partir de 2012 pois, com base nos dados, a partir desse ano, a mineração apresentava uma certa regularidade.

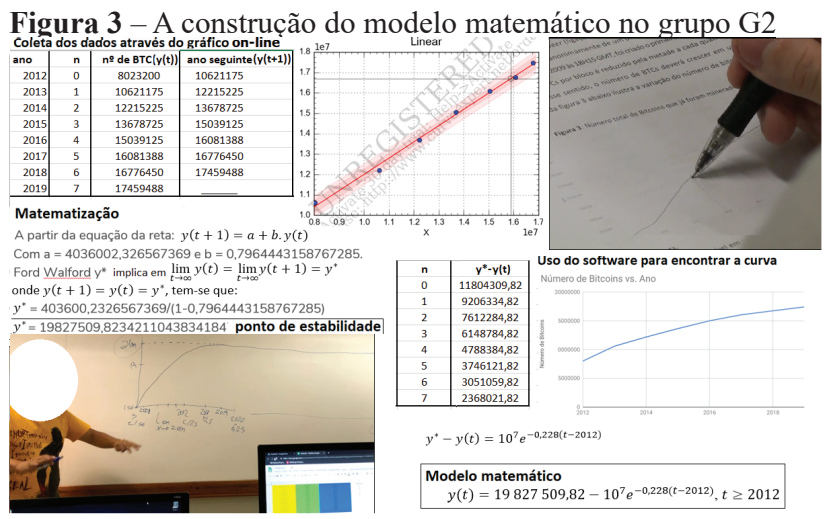

Fonte: As autoras.

Como incorporar essa informação, ou melhor, como fazer dessa hipótese um guia para resolver o problema, era uma situação nova para todos os alunos do grupo. Somente pela intermediação da professora, remetendo a conteúdos já abordados na disciplina de CDI, é que avançariam na matematização da situação. Entretanto, a menção ao uso de limites aparecia nas discussões dos alunos, conforme sugere o diálogo a seguir.

G2A4: É isso que a gente tem que achar, a gente pensou mesmo que tinha a ver com limite, por que ela faz assim (fazendo gestos com a mão, 'imitando' a curva).

G2A3: Sim, que é aquele tipo limite que a gente quer achar... de 21 milhões (referindo-se a uma busca feita na internet do número de BTC a serem minerados).

G2A4: Não. É a curva que a gente quer achar!
A professora então aproveitou a oportunidade para introduzir o que se conhece na literatura como método de Ford-Walford ${ }^{5}$ para determinar o valor limite da moeda cuja existência já havia sido reconhecida pelos alunos. Inicialmente, entretanto, a professora esclareceu que este não é o que os alunos haviam chamado de valor limite, mas sim valor de estabilidade.

Assim, a matematização da situação e a construção do modelo foram assessoradas pela professora nesse momento do desenvolvimento da atividade usando conceitos já abordados na disciplina, tais como limite de uma função e assíntota de uma função. $\mathrm{O}$ que já sabiam sobre assíntota horizontal de uma função, nessa atividade foi usado para determinar o valor de estabilidade da moeda Bitcoin, considerando que a quantidade de moeda a ser comercializada é limitada e tem um valor de estabilidade.

O uso do método de Ford-Walford foi coordenado pela professora que orientou e assessorou os alunos na construção do modelo matemático usando o software CurveExpert ${ }^{6}$ nos ajustes realizados (Figura 3). Para usar o modelo com o tempo variando a partir do ano de 2012, ou seja, , o modelo matemático obtido foi escrito como: em que é o tempo em anos e é a quantidade de moeda Bitcoin minerada no ano $t$.

O modelo matemático construído foi validado pelos alunos e sua interpretação associada às possiblidades de usá-lo para estimativas futuras com relação à comercialização da moeda Bitcoin. Para isso os alunos usaram também a representação gráfica do modelo (Figura 4) construída usando o software GeoGebra ${ }^{7}$.

Figura 4 - Validação do modelo matemático

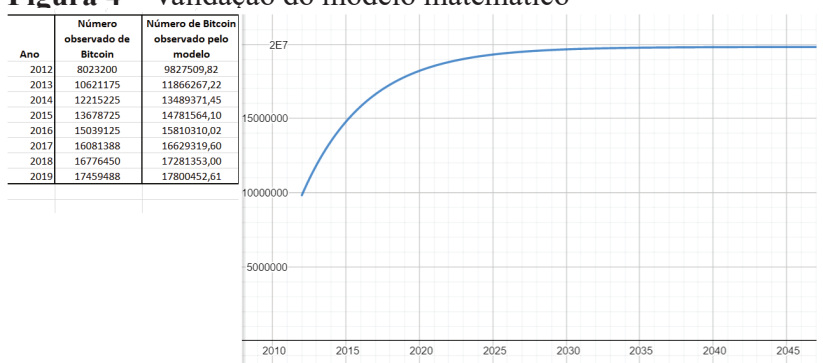

Fonte: As autoras.

A representação gráfica do modelo foi importante para os alunos entenderem a valor de estabilidade obtido vindo a lhes confirmar o que informações sobre o tema trazem na literatura, conforme aponta o relatório do grupo: "o modelo matemático encontrado trouxe resultados satisfatórios, pois nos dá que o valor da moeda se estabiliza em 1982750983 ou, aproximadamente, 20 milhões e nas nossas informações encontradas diz que esse valor é 21 milhões" (relatório da atividade entregue por G2).

Os alunos do outro grupo (G4), a partir da discussão das informações apresentadas pela professora, também 
recorreram à internet para decidir o que estudariam nessa atividade relativamente à moeda Bitcoin. Mediante essa ação, os alunos encontraram um gráfico que indica os valores da moeda no decorrer do tempo (Figura 5a).

Figura 5a - Investigação do problema

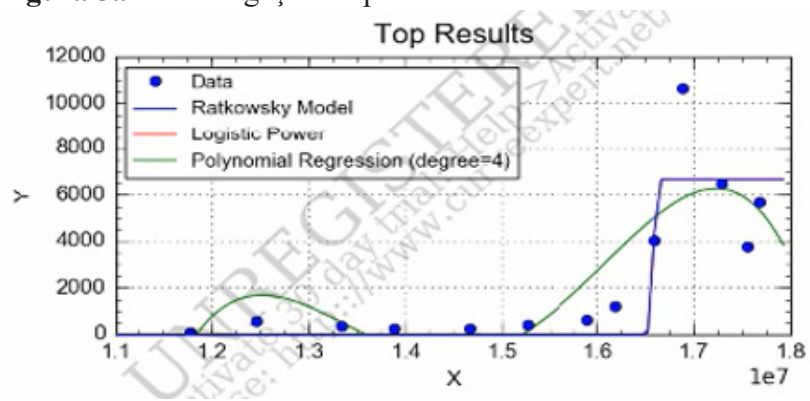

Fonte: Captura da tela do G4

Figura 5b - Uso do software para observar os dados coletados B Bitcoin Price (BTC)

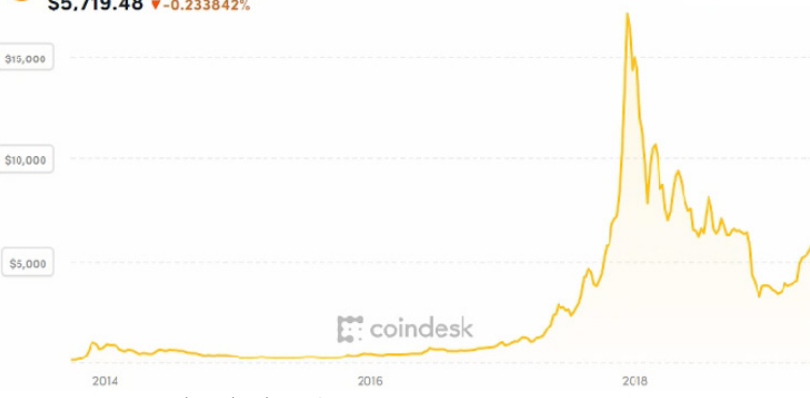

Fonte: Captura da tela do G4

Um dos alunos do grupo, G4A2, sugeriu que identificassem alguns pontos da curva da imagem da (Figura 5a) com o objetivo de encontrar uma relação entre a quantidade de moeda e o tempo. Ao escolher alguns pontos do gráfico, decidiram colocar os pontos no software CurveExpert (Figura $5 b)$ na expectativa de identificar uma maneira de determinar um modelo matemático. O diálogo a seguir ilustra parte da discussão dos alunos.

G4A2: Eu não estou vendo como a gente vai achar uma relação aqui, porque sobe um pouco e depois já desce e sobe de novo. O problema desta curva é que ela é muito 'repentina' em um curto intervalo de tempo, tipo... em um dia muda muito. É muito volátil! Não tem relação com a quantidade da moeda isso.

G4A1: Não vai dá pra gente tirar nenhuma conclusão você acha?

G4A2: Eu acho que é melhor a gente estudar a quantidade de moeda conforme o tempo vai passando.

Assim, os alunos do G4 concluíram que "[...] não pode se obter uma conclusão direta sobre a relação entre estas duas variáveis (moeda e tempo) devido a fatores externos que causaram uma grande variação da moeda em um curto período de tempo" - relatório escrito do G4.

Os alunos decidiram observar outras informações sobre a moeda que se encontravam no material entregue pela professora. O objetivo do grupo passou a ser observar a quantidade de moedas por bloco já que as minerações são feitas por blocos.
A partir desse problema, a informação que lhes parecia fundamental, entretanto, era a regularidade informada no material entregue pela professora: a partir de 2009, a quantidade de moedas por bloco estava reduzindo pela metade a cada 4 anos. Assim, decidiram investigar em que ano a moeda Bitcoin irá acabar, fato esse que foi fomentado da hipótese de que a produção de moeda Bitcoin é limitada. $\mathrm{O}$ diálogo a seguir revela a definição desse problema.

G4A1: Na verdade a gente tá vendo aqui que se a gente souber quanto que cada bloco produz de BTC por ano a gente vai achar quanto tem....

G4A2: Aqui ó: diz que cada bloco produz 12,5 BTC e, a cada 4 anos, cai pela metade... é como se fosse meia vida sabe?

G4A1: Não...mais ou menos...

G4A2: É que na verdade ele nunca vai parar de crescer, vai ser metade da metade da metade. Vai chegar numa fração de BTC que é tão pequena que vai demorar muito para chegar perto de 21 milhões, entendeu? Vai ser tipo um limite, sabe? (conteúdo que haviam estudado anteriormente na disciplina). Deve ser por isso que quanto mais ele é dividido mais caro ele fica.

A partir dessa discussão os alunos optaram pela construção de uma tabela (Figura 6a) usando para isso o software Excel, iniciando com 50 BTC e reduzindo pela metade a cada quatro anos. Aos dados da tabela foi associada uma representação gráfica usando o software CurveExpert (Figura 6b).

Figura 6a - Tabela com os dados

\begin{tabular}{|r|r|r|}
\hline Anos Passados & Tempo & Bitcoin por bloco \\
\hline 0 & 2009 & 50 \\
4 & 2012 & 25 \\
8 & 2016 & 12,5 \\
12 & 2020 & 6,25 \\
16 & 2024 & 3,125 \\
20 & 2028 & 1,5625 \\
24 & 2032 & 0,78125 \\
28 & 2036 & 0,390625 \\
32 & 2040 & 0,1953125 \\
76 & 2084 & 0,00009536743164 \\
80 & 2088 & 0,000047768371582 \\
140 & 2148 & 0,00000000145519 \\
144 & 2152 & 0,000000000072759 \\
148 & 2156 & 0,00000000036379 \\
152 & 2160 & 0,00000000018189 \\
156 & 2164 & 0 \\
\hline
\end{tabular}

Fonte: Relatório dos alunos

Figura 6b - Representação gerada software

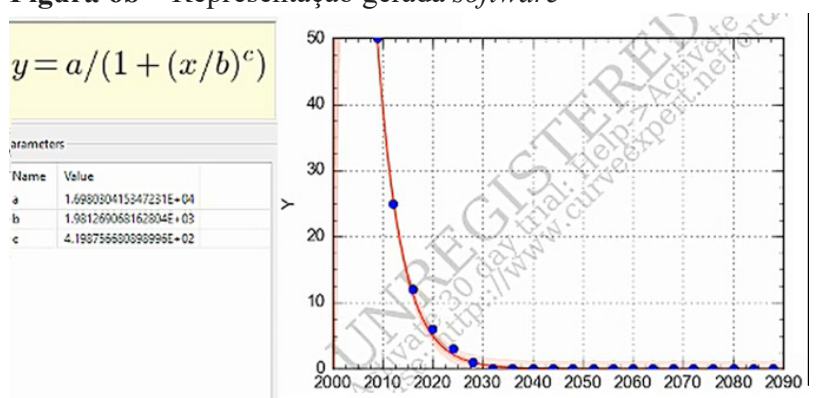

Fonte: Relatório dos alunos

O aluno G4A2, ao observar esta representação dos dados (Figura 6b) se manifestou dizendo que era diferente do que esperava, conforme ilustra o diálogo:

G4A2: Ah, mas não é isso... tinha que ser uma coisa diferente, essa é teoricamente a melhor do Curve porque porque passa nos pontos e tem esse coeficiente de correlação bom conforme a professora falou. Mas eu acho que tinha que ser uma PG na 
verdade. Quere ver? Cada vez divide por dois...

O aluno então expôs aos demais colegas do grupo o comportamento que observava nos dados, conforme indica a Figura 7 e a transcrição do diálogo a seguir.

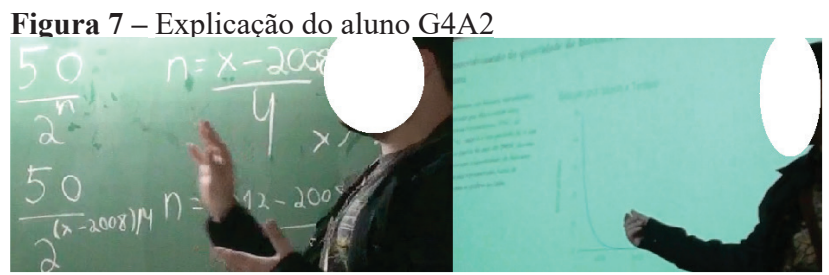

Fonte: As autoras.

G4A2: Para investigar a quantidade de moedas mineradas por bloco, eu acho que tem que pensar quanto tempo demoraria para que a quantidade de moedas mineradas fosse quase nula. Então a gente tem uma PG do tipo e n é um período de $4 \mathrm{em}$ 4 anos, porque a quantidade inicial é 50, e nesse tempo ela cai pela metade. Pra não ficar toda vez colocando de 4 em 4 anos, a gente faz .

G4A1: Mas daí o outro ano que tem é 2012!

G4A2: Mas então a gente pode fazer que é sempre no finalizinho do ano anterior e ai pra dar os 4 anos, vamos colocar 2008 ao invés de 2009. Daí a gente vai ter e assim vai dar certo.

Neste caso, a primeira representação gráfica não foi útil, mas motivou os alunos a construírem outro gráfico associado aos da tabela usando o Excel-uma vez que com esta ferramenta poderiam digitar a expressão matemática do modelo já obtida e construir sua representação gráfica (Figura 8).

Figura 8 - Gráfico construído usando o Excel

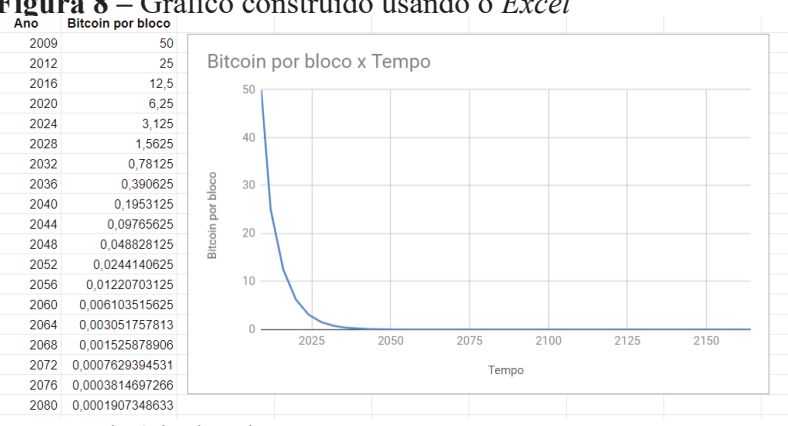

Fonte: Relatório dos alunos

Assim, a expressão geral do modelo para um ano qualquer superior a 2008, os alunos obtiveram o modelo matemático , em que $x$ é o tempo (dados em ano e e o quantidade de Bitcoin por bloco no ano .

Feitas essas considerações da resolução do problema, o grupo concluiu, em seu relatório final que: "conforme o nosso modelo matemático, a quantidade de BTC vai acabar no ano de 2164" - relatório escrito do G4.

\subsection{Recursos Semióticos na Atividade de Modelagem Matemática}

Para buscar indícios dos recursos semióticos ativados em atividades de modelagem matemática e como eles colaboram para o desenvolvimento da atividade, fazemos uma análise da ativação e usos destes recursos bem como de sua evolução no decorrer do desenvolvimento da atividade. Neste sentido, consideramos as ações dos alunos de forma holística, conjugando as análises sincrônica e diacrônica, conforme sugere Arzarello (2006).

O que se pode inferir a partir da apresentação do desenvolvimento da atividade pelos alunos é que em ambos os grupos foram ativados recursos semióticos diversificados tais como falas, gestos, software, calculadoras, lousa, registros escritos, gráficos.

Em cada fase do desenvolvimento da atividade de modelagem matemática, entretanto, a atividade semiótica foi se constituindo qualitativamente diferente, de modo que diferentes intenções, algumas vezes preexistentes à ativação do recurso semiótico, ativaram recursos específicos que colaboraram para as ações nesta fase bem como para a continuidade vislumbrada em outra fase.

Neste sentido, o texto fornecido pela professora, os gestos, as falas e discussões entre os elementos de cada grupo na fase de inteiração, constituem um pacote semiótico (pacote 1) em que os recursos de forma articulada atuavam visando avançar na organização e entendimento da situação e da formulação de um problema a ser resolvido. Os alunos do grupo G2, neste momento, tinham a intenção buscar mais informações para entender como uma moeda diferente daquela nacionalmente conhecida por todos poderia ser comercializada. O diálogo a seguir dá um indício de como o grupo se valia do recurso da fala, dos gestos, das representações gráficas fornecidas pela professora bem como daquelas que por meio de acesso à internet o grupo havia obtido.

G2A2: A gente pode pensar que a moeda é como o nosso dinheiro, os dois tão aqui... (Figura 9a) aí... não tá tão popular, fica mais barato e quando tiver maior procura, o preço vai lá em cima (Figura 9b), a gente pode fazer isso até estabilizar, nesta curva aqui (fazendo gestos imitando o comportamento da curva exibida na tela do computador Fig. 9c)

G2A3: Tá, mas como que a gente vai saber o preço da moeda todo dia? Desde quando? É muita coisa!

G2A1: Então...porque isso nunca vai ficar estável. Coloca lá no site que calcula o valor do BTC... tá vendo? A moeda divide bem mais que o dinheiro... um BTC pode ser 0,00000001 .

Nesse episódio os gestos associados ao discurso de G2A2 (Figura 9) aparentemente tornaram o problema compreensível para os alunos do grupo. O aluno, ao imitar o traçado da curva com a mão atuou de maneira a organizar o pensamento dos alunos, o que provocou uma mudança na estrutura do pacote (1), estabelecendo um novo pacote (2).

Conjuntamente os recursos semióticos ativados tais como o uso de gráficos e testagem de valores usando a calculadora de BTC a que tiveram acesso no site da internet lhe possibilitou pensar na definição do problema. A manipulação e a relação entre estes diferentes recursos tornou o pacote mais rico por favorecer a visualização dos dados na tela do computador. $\mathrm{O}$ que se pode inferir também nas imagens da Figura 9 é uma aparente sintonia entre os elementos do grupo de modo que o aluno G2A2 é capaz de antecipar a declaração do grupo 
ao surfar com a mão junto à tela do computador (Figura 9c). Neste sentido, o aluno compartilha o pacote semiótico com os demais alunos do grupo.

Figura 9 - Argumentações do aluno A2 sobre o valor monetário da moeda

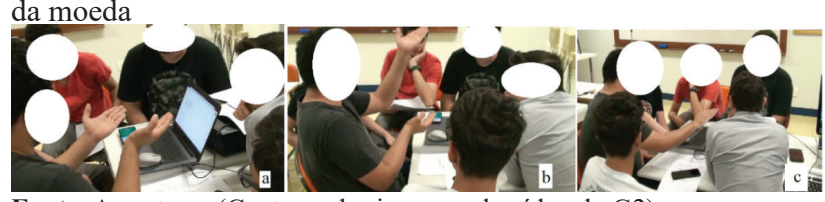

Fonte: As autoras (Capturas das imagens de vídeo do G2)

Ao estabelecer um entendimento comum em relação ao que pretendiam investigar, os alunos do G2, envolvidos com os recursos semióticos ativados anteriormente, começaram a fazer inscrições e escritas matemáticas que, associados com os recursos anteriores contribuíram para o incremento do pacote semiótico, constituindo um pacote formado por gestos, gráficos, software, esboços e apontamentos - pacote semiótico (3) (Figura 10).

Figura 10 - Os novos recursos para formar o pacote semiótico (3)

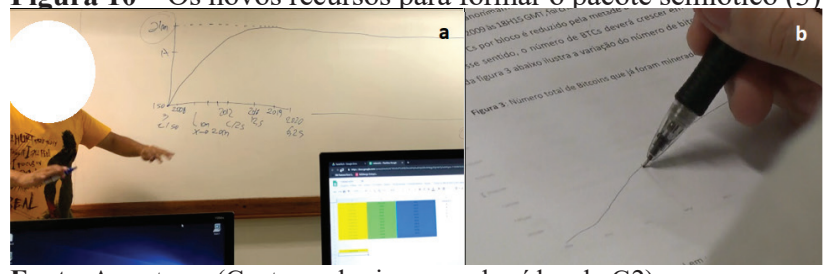

Fonte: As autoras (Capturas das imagens de vídeo do G2)

Do ponto de vista do desenvolvimento da atividade, estes recursos de traçar no ar as curvas e depois representa-las no papel foram fundamentais para que a hipótese de que se trata de um fenômeno que é limitado e que lhe deve ser associado um valor de estabilidade fosse definida e compreendida pelos alunos.

A partir dessa hipótese, a matematização da situação requereu a intervenção da professora. Esta intervenção, mediada por gestos, falas, escritas e uso de software para viabilizar aos alunos o uso do método de Ford-Walford, constitui uma relação entre recursos de forma a complementálos. Neste sentido, o pacote semiótico (pacote 4) se amplia tanto em termos da variabilidade de recursos quanto na estruturação de relações entre eles.

Durante a resolução do problema, além da escrita e do registro das relações matemáticas, os alunos usaram planilhas eletrônicas e o software CurveExpert. Porém, as ações do grupo ao validarem o modelo matemático, modificou o pacote semiótico. Os alunos escolheram o software GeoGebra para inserir a curva, ou seja, o modelo matemático que haviam encontrado. Essa ação tinha como intuito verificar a existência de uma assíntota ao arrastarem a curva exibida na tela (pacote semiótico 5).

Considerando uma análise diacrônica, ponderamos que os pacotes (1), (2),(3), (4) e (5) constituídos no decorrer do desenvolvimento da atividade orientaram grande parte do que os alunos foram capazes de realizar sem a intervenção da professora (pacotes (1), (2), (3)) bem como o que realizaram a partir do que essa intervenção acrescentou ao que já conheciam relativamente aos conceitos de limite e de assíntota de uma função. (pacotes (4) e (5)). Observamos que recursos semióticos como fala, gestos, imagens ativados pelas professora produziram um significado intuitivo nos alunos relativamente ao que pretendiam estudar. Quando esses recursos foram associados às expressões matemáticas e às imagens exibidas na tela do computador, provocaram a tomada de decisão, fazendo com que os signos operassem de forma independente e também de forma complementar.

A análise sincrônica, que considera a relação entre os recursos semióticos ativados simultaneamente nos diferentes pacotes, nos leva a inferir que a articulação entre os recursos semióticos específicos para a definição da hipótese, a matematização, a resolução e a validação viabilizou a comunicação entre os alunos do grupo e também que a relação entre imagens, tabelas, gráficos fosse cuidadosamente usada para resolver o problema. De fato, o gráfico, por exemplo, foi construído usando informações das tabelas construídas com os dados coletados e, a partir disso, esboços e relações matemáticas foram evidenciadas. A mediação semiótica desses recursos resultou em anotações compartilhadas na lousa e papel (Figura 3). A manipulação desses recursos provocou alguns insights nos alunos do grupo: inserir a mesmo modelo matemático em outro software na intenção de evidenciar características do fenômeno que ainda não haviam sido percebidas. A substituição de um recurso por outro mostra a intenção na modificação dos elementos do pacote como, por exemplo, a troca de um software por outro para validar o modelo matemático construído. Essa ação também evidencia que o pacote semiótico quando compartilhado com o grupo pode ativar a memória de eventos anteriores (no caso, o estudo de limites e de assíntotas), usando simultaneamente manipulação do software e registro algébrico do modelo (pacote semiótico (5)).

Podemos inferir que o desenvolvimento da atividade foi fortemente amparado pelo uso da tecnologia. Esta ação pode estar relacionada ao que Lim (2019) classifica como convergência semântica, considerando que a consciência do que deveriam fazer na situação em estudo na atividade evoluiu para as cognições e interpretações familiares aos sujeitos (alunos de um curso de Ciência da Computação), provocando complementaridades nos pacotes semióticos. Esta evolução e complementaridade dos recursos semióticos constituindo pacotes semióticos ativados por G2 está ilustrada na Figura 11.

Figura 11 - Esquema da constituição do pacote semiótico do grupo G2

\begin{tabular}{|c|c|c|c|c|}
\hline $\begin{array}{l}\text { PACOTE 1 } \\
\text { QR Code } \\
\text { gestos } \\
\text { fala } \\
\text { computador } \\
\text { celular }\end{array}$ & \begin{tabular}{|l} 
PACOTE 2 \\
gestos \\
fala \\
gráfico \\
calculadora
\end{tabular} & $\begin{array}{l}\text { PACOTE } 3 \\
\text { gestos } \\
\text { gráficos } \\
\text { software } \\
\text { esboço } \\
\text { apontamentos }\end{array}$ & $\begin{array}{l}\text { PACOTE } 4 \\
\text { gráfico } \\
\text { software } \\
\text { esboço } \\
\text { escrita }\end{array}$ & $\begin{array}{l}\text { PACOTE 5 } \\
\text { software } \\
\text { CurveExpert } \\
\text { software } \\
\text { GeoGebra } \\
\text { escrita }\end{array}$ \\
\hline
\end{tabular}

Fonte: As autoras. 
Para o grupo G2 a ativação de recursos semióticos e sua colaboração para o desenvolvimento da atividade de modelagem se realizou de forma concomitante, mas também complementar no decorrer das fases do desenvolvimento da atividade de modelagem matemática. Em cada substituição de recursos ou inclusão de outro recurso semiótico foram se constituindo os pacotes semióticos conforme sugere a Figura 12.

Figura 12 - Pacotes semióticos nas fases da modelagem matemática.

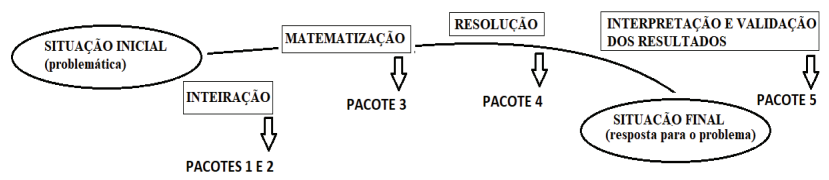

Fonte: As autoras.

O desenvolvimento da atividade pelo grupo G4 iniciou com um encaminhamento diferente do grupo G2. No G4 um aluno, G4A2, tomou para si a responsabilidade de proporcionar a inteiração dos alunos do seu grupo com a temática Bitcoin. Para isso ativou os recursos internet e site, que aliados aos recursos gestos e falas, se tornariam o pacote semiótico (pacote 1) e tinham a intenção de inteirar os alunos da situação, vindo a apresentar para seus colegas a imagem conforme sugere a Figura 5a. Em seguida informações que pareciam aparentes nesta imagem já foram associadas a outro recurso semiótico: um software para plotar pontos identificados na imagem (Figura 5b).

A articulação destes dois recursos, mediada por outros recursos (gestos, falas), foi suficiente para os alunos perceberam que estes seriam insuficientes para solucionar o problema proposto. Assim, comparações entre as imagens das figuras $5 \mathrm{a}$ e $5 \mathrm{~b}$, ativaram outro recurso semiótico, outro software capaz de testar valores e editar os parâmetros para o modelo que pretendiam construir. Assim, constitui-se o pacote semiótico (2).

A dinâmica dos recursos dos pacotes semióticos (1) e (2) está associada à intencionalidade do aluno G4A2 que se apoiava em gestos, falas e registros escritos na lousa para comunicar ao grupo suas intenções para a abordagem do problema. $\mathrm{O}$ aluno parecia controlar a variedade de recursos ativados e organizar o pensamento matemático dos demais alunos do grupo, ampliando os elementos do pacote. Suas intenções eram claramente encontrar meios para expressar seu conhecimento e apontar que uma progressão geométrica poderia descrever a quantidade de moeda restante para mineração em cada período de quatro anos (Figura 7). Convencer seus colegas desse comportamento e encontrar uma maneira de expressar os dados discretos da progressão em uma função contínua em que a variável $x$ indica um tempo qualquer a partir do ano de 2009, ativou nesses alunos outros recursos semióticos para além do que até então lhes era suficiente. A matematização foi viabilizada pela identificação do comportamento dos dados descrito por uma progressão geométrica. Entretanto, a fase de resolução em que o modelo contínuo seria construído requereu o que Ernest (2006) especificou como o terceiro aspecto relativo a um sistema semiótico, em que os recursos semióticos proporcionam a relação entre signos e seus significados. Assim, as duas imagens da Figura 9 indicam como os diferentes recursos ativados proporcionaram o desenvolvimento da atividade, ativando meios para matematizar a situação e construir um modelo matemático, constituindo o que chamamos de pacote semiótico 3.

Uma análise sincrônica dos dados nos permite inferir que o gráfico associado com a fala e os gestos - pacote semiótico (4) - potencializou o uso de diferentes recursos semióticos, evidenciando aspectos multimodais do processo de aprendizagem. Os quatro pacotes semióticos evidenciados no desenvolvimento da atividade de modelagem matemática pelo grupo G4 estão apresentados na Figura 12.

Figura 12 - Esquema da constituição do pacote semiótico do grupo G4

\begin{tabular}{|l|l|l|l|l|}
$\begin{array}{l}\text { PACOTE 1 } \\
\text { fala } \\
\text { gestos } \\
\text { internet } \\
\text { site }\end{array}$ & $\begin{array}{lll}\text { PACOTE 2 } \\
\text { fala } \\
\text { gestos } \\
\text { software } \\
\text { gráfico }\end{array}$ & $\begin{array}{l}\text { PACOTE 3 } \\
\text { gestos } \\
\text { software } \\
\text { gráfico } \\
\text { esboco } \\
\text { registros na lousa }\end{array}$ \\
\hline
\end{tabular}

Fonte: As autoras

A identificação dos pacotes semióticos no decorrer das diferentes fases do desenvolvimento da atividade por esse grupo nos leva a identificar uma espécie de intersecção entre os pacotes, o que não aconteceu com o grupo analisado anteriormente. Por exemplo, a intersecção dos pacotes (2) e (3) aconteceu justamente quando houve a necessidade de matematizar, porém os alunos trabalhavam ora com o pacote (2), ora com o pacote (3). Nesse mesmo sentido, os pacotes (3) e (4) também eram usados com duas finalidades de modo que os identificamos em duas fases diferentes do desenvolvimento da atividade. O esquema a seguir indica os pacotes semióticos associados às diferentes fases da modelagem matemática ( Figura 13).

Figura 13 - Fases da Modelagem Matemática com inserção dos pacotes semióticos $(\mathrm{G} 4)$

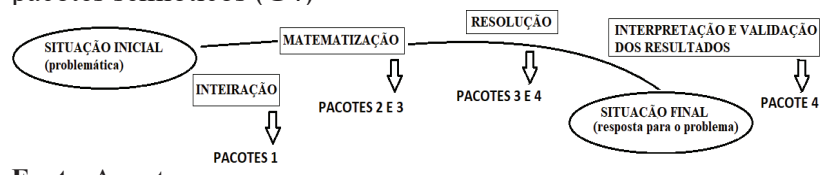

Fonte: As autoras.

Podemos considerar que em cada pacote semiótico os recursos ativados não atuaram de forma isolada, mas colaboraram para o desenvolvimento da atividade em cada fase de modo complementar e concomitante. Neste sentido, falas, gestos, e esboços em geral eram associados a outros recursos como gráficos, informações da internet, por exemplo, de modo que associados é que estes recursos colaboram para que os alunos, em um processo dinâmico, realizassem as ações relativas a cada fase da modelagem matemática. A 
não linearidade das ações nessas fases também foi mediada e orientada pelos recursos que complementaram uns aos outros no decorrer do desenvolvimento da atividade.

Em particular, observamos que o uso da tecnologia foi fortemente acionado pelos alunos que fizeram uso desse recurso para diferentes propósitos. Neste sentido, entendemos que o ambiente em que o aluno está inserido amplia e viabiliza a variedade de recursos semióticos acionados, em sintonia com as argumentações de Mavers (2004) de que a atividade semiótica é também contextual.

\section{Considerações Finais}

A investigação dos recursos semióticos ativados em atividades de modelagem matemática e como eles colaboram para o desenvolvimento da atividade realizada nesta pesquisa nos permite inferir que a combinação de diferentes recursos e de recursos associados a diferentes sistemas semióticos incrementa as ações dos alunos no desenvolvimento de atividades de modelagem matemática.

A ativação dos recursos semióticos bem como a sua colaboração para o desenvolvimento da atividade de modelagem matemática é ao mesmo tempo sincrônica e diacrônica de modo que não é possível afirmar especificamente quando um recurso atua de forma isolada ou conjuntamente com outros para potencializar a comunicação e organizar o pensamento.

A conexão entre os diferentes recursos semióticos constitui pacotes semióticos e foi apoiada também pelo resgate de ideias matemáticas e experiências anteriores dos alunos com os conteúdos que emergiram nessa atividade de modelagem matemática. Além disso, diferentes recursos não se constituem de maneira isolada, mas são complementados na medida em que a cooperação entre os alunos do grupo e a interação com informações relativas à temática investigada na atividade foi acontecendo nos grupos. A assessoria da professora foi fundamental para que recursos semióticos fossem acionados e usados de forma colaborativa para resolver o problema.

Uma implicação dos resultados dessa pesquisa é que olhar para o pacote semiótico nos fornece elementos para evidenciar a intencionalidade dos alunos na ativação de diferentes recursos semióticos e seu uso conjunto e articulado para colaborar em cada fase do desenvolvimento da atividade de modelagem matemática. Assim, em sintonia com a assertiva de Arzarello (2006, p. 279), de que "uma atividade matemática pode ser caracterizada pela riqueza do pacote semiótico que ela ativa" consideramos que atividades de modelagem matemática têm potencial para requerer e acionar uma variedade de recursos semióticos. Não obstante esta ativação, as ações dos alunos nas diferentes fases da modelagem ampliam a perspectiva de um uso isolado de cada recurso, tornando possível a constituição de pacotes semióticos em que os diferentes recursos se articulam e se complementam.

\section{Referências}

Abbagnano, N. (2007). Dicionário de filosofia. São Paulo: Martins Fontes.

Almeida, L. M. W., Silva, K.A. P. (2018a). Abordagens Semióticas em Educação Matemática. Boletim de Educação Matemática. Bolema, 32, 696-726.

Almeida, L. M. W., Silva, K. P., Vertuan, R. E. (2016). Modelagem Matemática na Educação Básica. São Paulo: Contexto.

Almeida, L. M. W. (2010). Um olhar semiótico sobre modelos e modelagem: metáforas como foco de análise. Zetetiké, 18, 387-414.

Almeida, L. M. W. (2018). Considerations on the use of mathematics in modeling activities. ZDM, 50, 19-30.

Almeida, L. M. W., Brito, D. S. (2005).Atividades de Modelagem Matemática: que sentido os alunos podem lhe atribuir? Ciência e Educação. 11, 1-16.

Almeida, L. M. W., Silva, K. A. P. A (2017). Ação dos Signos e o Conhecimento dos Alunos em Atividades de Modelagem Matemática. Bolema, 31, (57) 202-219.

Arzarello, F. (2006). Semiosis as a multimodal process. Relime, 267-299.

Arzarello, F., Paola, D., Robutti, O., Sabena, C (2009). Gestures as semiotic resources in the mathematics classroom. Educational Studies in Mathematics, p.97-109.

Bassanezzi, R. C. (2002). Ensino-aprendizagem com modelagem matemática: uma nova estratégia. São Paulo: Contexto.

Blum, W. (2015). Quality teaching of mathematical modelling: What do we know, what can we do? In: S. J. Cho. The Proceedings of the 12th International Congress on Mathematical Education: Intellectual and Attitudinal Changes, pp.73-96. New York: Springer

Ernest, P. (2006). A semiotic perspective of mathematical activity: The case of number. Educational Studies in Mathematics, (61), 67-101.

Ferri, R. B. (2018). Learning how to teach mathematical modeling in school and teacher education. Picassoplatz, Switzerland: Springer.

Galbraith, P. (2012). Models of Modelling: Genres, Purposes or Perspectives. Journal of Mathematical Modelling and application, 1,(5), 3-16.

Greefrath, G., Hertleif, C., Siller, H-S. (2018). Mathematical modelling with digital tools - a quantitative study on mathematising with dynamic geometry software. ZDM, 1-12.

Lim, F. V. (2019). Investigating intersemiosis: a systemic functional multimodal discourse analysis of the relationship between language and gesture in classroom discourse. Visual Comunication, 2-25.

Mavers, D. E. (2004). Multimodal design: the semiotic resources of children's graphic representation. Londres: Universidade de Londres.

Meyer, J.F.C. (2020). A. Modelagem Matemática: O desafio de se 'fazer' a Matemática da necessidade. Com a Palavra o Professor,5, (11).

Mildenhall, P. M. (2013). Using semiotic resources when building images of the part-whole model of fractions. Conference of Mathematics Education Research Group of Australasia. MERGA: Melbourne.

Moro, L., Mortimer, E. F., Quadros, A. L., Coutinho, F. A. (2015). 
Influência de um terceiro modo semiótico na gesticulação de uma professora de Química. Revista Brasileira de Pesquisa em Educação e Ciências. 15, (1),9-32.

O'Halloran, K., Beezer, R. A., Farmer, D. W. (2018). A new generation of mathematics textbooks research and development. ZDM, 50 , (5), 863-879.

P Panero, M.; Arzarello, F.; Sabena, C. (2016). The Mathematical Work with the Derivative of a Function: Teachers' Practices with the Idea of "Generic". Bolema, 30, (54), 265-286.

Radford, L., Schubring, G., Seeger, F. (2008). Semiotics in
Mathematics Education: Epistemology, history, classroom and culture. The Netherlands: Sense Publishers.

Stillman, G.; Brown, J.; Galbraith, P. (2010). Identifying challenges within transition phases of mathematical modeling activities at year 9. In R. Lesh, P. Galbraith, C. R. Haines, \& A. Hurford. Modeling students' mathematical competencies, pp.385-398. New York: Springer.

Steinbring, H. (2006). What Makes a Sign a Mathematical Sign? An Epistemological Perspective on Mathematical Interacion. Educational Studies in Mathematics, 61, (1/2), . 133-162. 